УДК 338.2:55398

\title{
ОПТИМАЛЬНАЯ СТРАТЕГИЯ ВЫБОРА ПОДРЯДЧИКА КРУПНЫХ КАПИТАЛЬНЫХ НЕФТЕГАЗОВЫХ ПРОЕКТОВ
}

\author{
Давыденков Евгений Владимирович, \\ evdavydenkov@gmail.com \\ О०О «Газпромнефть-НТЦ», \\ Россия, 190000, г. Санкт-Петербург, наб. реки Мойки, 75-79, лит. Д.
}

\begin{abstract}
Актуальность работы заключается в изменении принципов и подходов определения партнеров для реализации крупных капитальных нефотегазовых проектов.

Целью работы является обоснование трансформации принципов взаимоотношений нефртегазовых компаний с подрядчиками несртегазовых проектов для совместного решения стратегических бизнес-задач.

Методы исследования заключаются в оптимизации проектных решений на основе логических построений концепции продуктовой модели деятельности нефртегазовых компаний.

Результаты. Наиболее оптимальным способом выбора взаимоотношений с подрядчиками и поставщиками может быть стратегия контрактования. А для крупного капитального проекта - интегрированная стратегия контрактования. Она представляет собой документ, содержащий интегрированный план реализации проекта, карту контрактов $\mathrm{c}$ необходимым количеством подрядчиков и поставщиков и подходы к их выбору, проработанный в том числе с учетом возможных синергий по контрактам и, возможно, проектам. В определении стратегии выбора подрядчиков и поставщиков необходимо учитьвать: их текущий опыт взаимодействия с компанией и с другими заказчиками, их текущую загрузку обязательствами перед компанией, текущие мощности подрядчика или поставщика, его возможности по наращиванию таких мощностей, способность подрядчиков осваивать и управлять финансовыми потоками, опыт выполнения работ будущими подрядчиками в схожих условиях.

Выводы. Необходимо создание контрактной стратегии и моделей взаимоотношений с подрядчиками крупных капитальных нефртегазовых проектов начиная с ранних стадий, преемственности при переходе от стадии к стадии реализации проекта, проработки условий взаимодействия и последующего управления договорами. Все эти аспекты должны быть учтены в соответствующей интегрированной стратегии контрактования, которая станет сводным документом по управлению взаимоотношениями с подрядчиками, а также инструментом по контролю и управлению потребностью проекта. Максимальная гибкость проекта в отношениях с подрядчиками будет обеспечиваться через соответствующие механизмы - открытье договоры, условия ценообразования и мотивации подрядчиков. Новая система определения партнеров для реализации крупных капитальных нефтегазовых проектов успешно адаптирована в ПАО «Газпром нефрть».
\end{abstract}

\section{Ключевые слова:}

Крупный нефтегазовый проект, управление проектом, стратегия снабжения, рамочный договор, выбор подрядчиков.

\section{Введение}

В настоящее время нефтяная отрасль страны переживает эпоху реализации сложных инфраструктурных проектов. Это связано с ростом инвестиционных возможностей, а также с необходимостью компенсировать падение добычи нефти на зрелых месторождениях. При этом нефтяные компании сегодня работают как в своих традиционных регионах, так выходят в новые - месторождения на суше и на море. По прогнозам в ближайшие годы нефтяные компании страны будут добывать около 20 \% объема нефти в новых регионах с неразвитой инфраструктурой. Это потребует значительных инвестиций в их освоение - по некоторым прогнозам более 200 млрд долл. в течение 10 лет $[1,2]$.

\section{Современное стояние нефтегазового проектирования}

Существующий опыт и подходы, применяемые при реализации крупных инфраструктурных проектов, позволяют их реализовывать, но при этом нефтяники продолжают сталкиваться с существенными трудностями Практически все нефтяные компании сегодня применяют проектный метод реализации крупных капитальных проектов, однако в разных объемах проблемы его применения наблюдаются во всех проектах [3-7].
Одной из ключевых проблем остаются сроки реализации проекта. По оценкам экспертов срок реализации крупного капитального проекта западными нефтяными компаниями короче на 3-5 лет, чем аналогичный в России. И этому есть много причин. Одна из них - недостаточность и квалификация сотрудников проектных команд в компаниях. Другая - длительность проработки предпроектных стадий и низкое качество результата, что в последствии не позволяет управлять сроками и затратами проекта [7-11].

Второй ключевой проблемой является непрогнозируемость бюджета реализации проектов. Практически каждый проект, реализованный в России, завершается с превышением бюджета от первоначального на 20-30 \%, а некоторые и более $[8,11]$. И тому тоже есть несколько причин.

Одна из них - отсутствие опыта и достаточных возможностей для проработки всех возможных альтернатив реализации проекта, как с технической точки зрения, так и с точки зрения опыта уже реализованных проектов. Работы, проводимые на начальных стадиях проекта по его проектированию и планированию, ведутся либо силами служб компанийзаказчиков, а у них нет достаточного опыта и проработок, чтобы выбрать самый оптимальный и эффек- 
тивный способ его реализации, либо привлеченными подрядчиками, а именно, в подавляющем большинстве случаев, проектными институтами, которые в нашей стране давно не занимаются инжиниринговыми проработками проектов и объектов, а проектируют «потоковые» объекты (реконструкция или расширение существующей инфраструктуры), где от персонала проектного института не требуется применение инновационных, наиболее эффективных инженерных решений $[8,11]$. Все это приводит к тому, что, когда проект выходит в стадию «реализации», принятые ранее решения пересматриваются, дорабатываются, что ведет к росту бюджета и движению сроков по проекту. Особенно это проявляется именно в новых для нефтяной компании регионах, где не изучены вопросы геологии, логистики, ресурсов и т. п.

Другая причина в самих подрядчиках и поставщиках, которые привлекаются для реализации проекта. Не секрет, что многие нефтяные компании привыкли выбирать подрядчика или поставщика проводя конкурентные процедуры, по результатам которых наиболее вероятным победителем станет подрядчик, предложивший минимальную стоимость реализации проекта. И тут начинается самое интересное: заказчик рассчитывает на то, что подрядчик в должной мере изучил все риски реализации проекта и «понимает» куда идет, а подрядчик, выиграв такой контракт, начинает понимать все нюансы и возможные трудности с его реализации по ходу его выполнения. И тут есть много вопросов: это и качество проработки технического задания самим заказчиком, и время на подготовку предложения подрядчиком, и полнота данных о проекте и площадке, но и со стороны подрядчика отсутствие опыта и наработанной базы реализации таких проектов в схожих регионах, для грамотной и полной оценки рисков и стоимости, это и неумение управлять такими масштабными проектами, что видно по самим структурам таких подрядчиков, в которых отсутствуют выделенные ресурсы по проектному планированию, оценки эффективности, инженерные мощности и т. п. Все это ведет к тому, что в процессе реализации проектов и заказчик и подрядчик учатся на конкретном проекте, что приводит к соответствующему снижению эффективности [11].

Помимо этого, существует противоречие между мотивациями проектных организаций, привлекаемых для реализации проектов, и подрядчиками/поставщиками, которые также существенным образом влияют на последующий процесс строительства объекта и реализации проекта в целом. Ключевое противоречие в том, что движет проектными институтом при проектировании объекта. Зачастую это минимизация своих расходов на проработку решений, т. к. после победы в конкурсе на проектирование в конкурентной борьбе, стоимость работ снижается так, что возможносьи для детальной проработки проекта не остается, а остается только взять с «полки» уже имеющийся проект, поменять штамп и направить проект на экспертизу заказчику, а заказчик также не всегда задумывается над качеством именно инженерной проработки, а сосредотачивается на получении положительного заключения Главгосэкспертизы, чтобы потом получить разрешение на строительство и приступить к работам. Подрядчик, или же поставщик, являясь потребителем разработанного проекта и последующей рабочей документации, приступив к выполнению работ, находится перед выбором: либо сделать все по чертежу и получить неоптимальную, а может и нерабочую схему, и вступить с заказчиком в долгие судебные разбирательства, либо сделать все, как надо, что повлечет необходимость самостоятельной переделки проекта, предложения его заказчику, а у заказчика согласования с автором и так далее, вплоть до повторного прохождения экспертизы. В итоге вместо того, чтобы получить оптимальный с экономической и технической точки зрения объект, все стороны вынуждены искать компромисс между собственной репутацией, бюджетом проекта и сроками его реализации.

\section{Разработка решений по выбору}

\section{подрядчиков нефтегазовых проектов}

Одним из способов повышения интегрированности решений, принимаемых в проекте, их увязка с возможностями подрядчиков, проработка наиболее оптимальных подходов к их контрактованию, может быть интегрированная стратегия контрактования для крупного капитального проекта. Сегодня во многих компаниях уже применяются такие инструменты взаимодействия с рынком, как стратегия контрактования, однако при реализации крупного капитального проекта с таким подходом есть несколько ограничений: одно из них в том, что стратегии разрабатываются для отдельных видов материалов и оборудования или услуг и по мере развития проекта при возникновении соответствующих потребностей, однако такой подход не позволяет увидеть всю полноту потребности по проекту, определить наиболее эффективный и своевременный способ ее размещения на рынке подрядчиков и поставщиков. Это приводит к множеству циклов выбора подрядчиков, постоянному изменению потребности, что, в свою очередь, ведет либо к новой процедуре выбора подрядчиков, либо к изменению ранее заключенных контрактов. По отдельным проектам объем таких изменений может достигать $40 \%$ от всей потребности по проекту. Все это ложится в снижение эффективности проекта и смещение сроков.

Интегрированная стратегия представляет собой документ, содержащий интегрированный план реализации проекта, карту контрактов с необходимым количеством подрядчиков и поставщиков, подходам к их выбору, проработанный в том числе с учетом возможных синергии по контрактам и, возможно, проектах (если речь идет о группе реализации группы проектов). Такой документ является настольной книгой для руководителя проекта и должен быть постоянно актуален.

Интегрированная стратегия должна быть разработана уже на этапе «выбор» и в последующем поддерживаться и актуализироваться. При ее разработке необходимо учитывать такие вопросы, как:

- частота возникновения потребности в том или ином материале, оборудовании или услуге; это 
будет влиять на сроки контрактов с подрядчиками и поставщиками, а также на возможности их изменения или уточнения по мере развития проекта;

- объем потребности; это влияет на количество необходимых подрядчиков или поставщиков; во3можности рынка подрядчиков или поставщиков, т. е. их способности выполнить поручаемый заказ;

- вопросы логистики в увязке со всеми грузопотоками по проекту, включая грузооборот заказчика и объем грузов, который заказчик планирует передать подрядчикам, т. к. это может впрямую влиять на необходимую к созданию инфраструктуру;
- другие вопросы, которые необходимо учесть службе снабжения крупного капитального проекта.

При этом ключевой компетенцией для службы снабжения при реализации крупного капитального проекта будет скорость реакции на запрос в соответствующем ресурсе. Для этого необходимо разрабатывать и использовать гибкие инструменты взаимодействия с подрядчиками и поставщиками, позволяющие быстро реагировать на заказы и управлять изменениями в объеме и сроках реализации проектов. Целесообразно применять такой инструмент, как карта контрактов, который позволяет управлять потребностью и распределять ее по соответствующим договорным обязательствам (рис. 1).

\begin{tabular}{|c|c|c|c|c|}
\hline $\begin{array}{l}\text { Вид услуг или материально- } \\
\text { технические ресурсы } \\
\text { Type of service or material }\end{array}$ & \multicolumn{4}{|c|}{$\begin{array}{l}\text { Объект реализации в составе проекта } \\
\text { Object of implementation as part of the project }\end{array}$} \\
\hline $\begin{array}{l}\text { Проектирование } \\
\text { Design }\end{array}$ & $\begin{array}{c}\text { Подрядчик } 1 \\
\text { Contractor } 1\end{array}$ & \multirow{3}{*}{$\begin{array}{l}\text { Подрядчик } 5 \\
\text { Contractor } 5\end{array}$} & \multicolumn{2}{|c|}{$\begin{array}{l}\text { Подрядчик } 6 \\
\text { Contractor } 6\end{array}$} \\
\hline $\begin{array}{c}\text { Строительно-монтажные работы } \\
\text { Construction }\end{array}$ & $\begin{array}{l}\text { Подрядчик } 2 \\
\text { Contractor } 2\end{array}$ & & $\begin{array}{l}\text { Подрядчик } 2 \\
\text { Contractor } 2\end{array}$ & $\begin{array}{c}\text { Подрядчик } 8 \\
\text { Contractor } 8\end{array}$ \\
\hline $\begin{array}{c}\text { Пусконаладочные работы } \\
\text { Commissioning }\end{array}$ & $\begin{array}{c}\text { Подрядчик } 3 \\
\text { Contractor } 3\end{array}$ & & \multicolumn{2}{|c|}{ Подрядчик 7/Contractor 7} \\
\hline $\begin{array}{c}\text { Поставка оборудования } \\
\text { Equipment supply }\end{array}$ & \multicolumn{2}{|c|}{$\begin{array}{c}\text { Поставщик } 1 \\
\text { Supplier } 1\end{array}$} & \multicolumn{2}{|c|}{$\begin{array}{l}\text { Поставщик } 3 \\
\text { Supplier } 3 \\
\end{array}$} \\
\hline $\begin{array}{l}\text { Поставка материалов } \\
\text { Supply of materials }\end{array}$ & $\begin{array}{l}\text { Поставщик } 2 \\
\text { Supplier } 2\end{array}$ & $\begin{array}{l}\text { Подрядчик } 5 \\
\text { Contractor } 5\end{array}$ & $\begin{array}{l}\text { Поставщик } 4 \\
\text { Supplier } 4\end{array}$ & $\begin{array}{l}\text { Поставщик } 2 \\
\text { Supplier } 2\end{array}$ \\
\hline $\begin{array}{c}\text { Строительный контроль заказчика } \\
\text { Technical supervision }\end{array}$ & \multicolumn{4}{|c|}{ Подрядчик 4/Contractor 4} \\
\hline
\end{tabular}

Pис. 1. Карта контрактов нефтегазового проекта

Fig. 1. Map of oil and gas project contracts

Кроме того, в определении стратегии выбора подрядчиков и поставщиков необходимо учитывать, что выбор ключевых подрядчиков, выполнение работ которых лежит на критическом пути проекта, необходимо осуществлять по совокупности знаний о подрядчике или поставщике. Например:

1. Учитывать его текущий опыт взаимодействия с компанией либо изучить опыт взаимодействия с другими заказчиками. Хорошим примером такого изучения могут стать референс-визиты на объекты, на которых подрядчик выполняет работы в настоящий момент.

2. Учитывать его текущую загрузку обязательствами перед компанией или другими заказчиками, так как это может стать ключевой проблемой для вашего проекта, если требования по обязательствам от других заказчиков будут усиливаться.

3. Учитывать не только текущие мощности подрядчика или поставщика, но и его возможности по наращиванию таких мощностей, так как срок реализации проектов длительный и в этот период у подрядчика или поставщика могут возникнуть новые обязательства.

4. Учитывать его способность осваивать и управлять финансовыми потоками в размере не менее среднего освоения по объекту/проекту в течение года.
Зачастую для подрядчиков это является невыполнимой задачей, с которой они не справляются, и появляются кассовые разрывы и задолженности по оплатам, с которым в последствии приходится справляться самому заказчику.

5. В случае если проект находится на труднодоступной территории, с отсутствием круглогодичного проезда, или в условиях экстремальных температур, опыт выполнения работ будущим подрядчиком в схожих условиях должен стать обязательным критерием выбора. Умение подготовить организацию к условиям работы в автономии или низких температур, обеспечить необходимый завоз и накопление топлива, материалов, питания, одежды и пр. - отдельная компетенция в менеджменте подрядчика. Если этого не учесть, то существует риск для заказчика в первый же сезон проводить операцию по спасению подрядчика, и не все подрядчики это переживают, а для проекта это смещение сроков, увеличение стоимости реализации и пр.

Это только ключевые критерии, на которые стоит обратить внимание при выборе подрядчика, а есть еще множество других, таких как: соответствие стандартам качества, наличие с структуре подрядчика необходимых для выполнения работ служб, соблюде- 
ние требований промбезопасности, применение которых должно быть детально проработано до принятия решения о выборе того или иного подрядчика для реализации проекта. Но с выбором качественного подрядчика все только начинается. Необходимо иметь соответствующий опыт взаимодействия с сильным подрядчиком и самому заказчику и уметь видеть в подрядчике своего партнера, который поможет реализовать проект, - это грамотная и дальновидная стратегия заказчика.
Для формирования основы таких отношений лучшей практикой считается заключение долгосрочного договора на реализацию проекта. Суть такого договора не в заключении его только на конкретный объект/стройку, а в возможности гибкого управления мощностями своего подрядчика/поставщика, когда условиями договора предусматривается возможность перемещения подрядчика на другой объект строительства без проведения дополнительных процедур выбора. Схема работы такого договора приведена на рис. 2.

\begin{tabular}{|c|c|c|c|c|c|c|}
\hline \multicolumn{7}{|c|}{$\begin{array}{l}\text { Основной договор на выполнение работ по проекту } \\
\text { ор содержит базовые условия взаимодействия сторон, включая: } \\
\text { / The main contract for the implementation of the project } \\
\text { ient contains basic conditions for the interaction of the parties, including: }\end{array}$} \\
\hline $\begin{array}{c}\text { Условия выдачи } \\
\text { заданий на объект/ } \\
\text { подобъект / } \\
\text { Conditions for } \\
\text { issuing tasks for } \\
\text { an object / subobject }\end{array}$ & $\begin{array}{c}\text { Условия } \\
\text { ценообразования / } \\
\text { Pricing terms }\end{array}$ & & $\begin{array}{l}\text { овия сдачи/ } \\
\text { мки работ / } \\
\text { is of delivery } \\
\text { acceptance } \\
\text { of work }\end{array}$ & $\begin{array}{r}\text { Условия } \\
\text { и са } \\
\text { Motivatic } \\
\text { and }\end{array}$ & $\begin{array}{l}\text { отивации } \\
\text { ций / } \\
\text { conditions } \\
\text { halties }\end{array}$ & $\begin{array}{c}\text { Условия и механизмы } \\
\text { оценки деятельности / } \\
\text { Performance Assessment }\end{array}$ \\
\hline \multicolumn{7}{|c|}{$\nabla$} \\
\hline \begin{tabular}{|l|} 
Задание на объект 1. \\
Условия задания содер- \\
жат детали выполнения \\
работ на объекте 1. \\
Стоимость работ сфор- \\
мирована на основании \\
условий, указанных в \\
основном договоре / \\
Objective 1. The terms \\
of the assignment contain \\
details of the performance \\
of work at facility 1
\end{tabular} & \multicolumn{2}{|c|}{\begin{tabular}{|l|} 
Задание на объект 2. \\
Условия задания содер- \\
жат детали выполнения \\
работ на объекте 2 . \\
Стоимость работ сфор- \\
мирована на основании \\
условий, указанных в \\
основном договоре / \\
Objective 2. The terms \\
of the assignment contain \\
details of the performance \\
of work at facility 2
\end{tabular}} & \multicolumn{2}{|c|}{\begin{tabular}{|l|} 
Задание на объект 3. \\
Условия задания содер- \\
жат детали выполнения \\
работ на объекте 3 . \\
Стоимость работ сфор- \\
мирована на основании \\
условий, указанных в \\
основном договоре / \\
Objective 3. The terms \\
of the assignment contain \\
details of the performance \\
of work at facility 3
\end{tabular}} & $\cdots$ & \begin{tabular}{|l} 
Задание на объект $\boldsymbol{n}$. \\
Условия задания содер- \\
жат детали выполнения \\
работ на объекте $n$. \\
Стоимость работ сфор- \\
мирована на основании \\
условий, указанных в \\
основном договоре / \\
Objective $n$. The terms \\
of the assignment contain \\
details of the performance \\
of work at facility $n$
\end{tabular} \\
\hline
\end{tabular}

Pис. 2. Схема долгосрочного договора подряда нефтегазового проекта

Pic. 2. Scheme of a long-term oil and gas project contract

Однако, если для реализации проекта необходимо привлечь несколько подрядчиков/поставщиков, и каждый из них будет работать по аналогичной договорной схеме, у системы снабжения должны появится инструменты управления такими договорами, например оценка деятельности подрядчика, управление долями рынка каждого подрядчика. Оценку деятельности целесообразно вводить при работе с длительными договорами, чтобы иметь возможность управлять качеством работ подрядчика/поставщика. Такая система отдельно прорабатывается и включается в условия соответствующих договоров. Не секрет, что если подрядчик/поставщик получит долгосрочный контракт на выполнение комплекса работ или большого объема поставки, в течение более полутора лет, это может явиться условием некоего успокоения подрядчика и через некоторое время качество его работ или материалов и оборудования начнет снижаться. Чтобы избежать этого и иметь возможность стимулировать деятельность подрядчика, вводятся соответствующие ключевые показатели эффективности, складывающиеся в систему оценки деятельности. Такими показателями могут быть:

- соответствие персонала и оборудования, имеющегося на объекте, условиям выполнения работ;
- показатели качества выполнения работ: процент брака, переделок; отступление от норм и правил, а также проектно-сметной документации по объекту;

- количественные показатели предписаний строительного контроля на объекте строительства (остановка работ, нарушение технологии и пр.);

- соблюдение сроков, предусмотренных договором;

- соблюдение норм и правил промышленной безопасности;

- соблюдение условий проживания работников подрядчика и т. д.

Для поставщиков это могут быть показатели брака, соблюдение сроков, скорости реагирования на запросы заказчика и т. д.

Введение механизма оценки деятельности позволяет своевременно реагировать на ухудшение ситуации у подрядчика (например, отрицательная динамика брака) и принимать оперативные меры, когда ситуацию еще можно исправить. Кроме того, такой механизм позволяет службе снабжения проекта управлять долями рынка подрядчиков. Приведем пример, в результате проведенного выбора подрядчиков для проекта у вас оказалось четыре подрядчика, имеющих на руках долгосрочные открытые договоры, каждый из них работает на конкретном участке работ, однако в 
определенный момент возникает потребность начать работы на новом объекте или нескольких объектах. Как распределить новый объем среди имеющихся подрядчиков? Отдать первому? Отдать всем по частям? Если отдать все одному, то остальные подрядчики не почувствуют заинтересованность в продолжении сотрудничества с вами и после завершения уже имеющих обязательств уйдут с проекта. Для вас это риски выбора новых подрядчиков, процесс привыкания подрядчика к заказчику, риск смещения сроков и т. д. Для того чтобы иметь объективный инструмент управления дополнительными объемами, вводится система управления долями рынка. Такая система позволяет завязать возможности подрядчика, его текущую загрузку и оценку деятельности с процессом принятия решения о распределении новых объемов работ. Как правило, условия распределения включаются в договор и являются прозрачными для подрядчика. В любой момент времени подрядчик понимает взаимосвязь своей текущей результативности с возможностью получения дополнительных объемов работ. В таком случае новый объем работ из нашего примера будет распределен подрядчику, имеющему лучшие показатели оценки деятельности и необходимые мощности для выполнения такого объема. Это позволяет равномерно загружать всех имеющихся у вас подрядчиков, минимизируя и распределяя риски.

Все эти условия и механизмы должны быть учтены в интегрированной стратегии для того, чтобы иметь возможность управлять всеми договорами, имеющимися на проекте. Отдельного рассмотрения заслуживает введение механизмов мотивации подрядчиков/поставщиков за ускорение, результат, оптимизацию стоимости или проектных решений. Такой мотивацией могут быть премии, дополнительные объемы, разделение прибыли и пр. Введение механизмов мотивации создает дополнительную ценность для проекта, которую может принести подрядчик/поставщик. Например, заказчик может предусмотреть в договоре возможность премии подрядчику за ускорение работ на объекте. Как правило, такая премия устанавливается для объектов, которые являются ключевыми для проекта и в результате ввода в эксплуатацию которых заказчик начинает извлекать прибыль. В таких случаях на этапе проработки договорных условий проект формирует требование о возможности ввода соответствующего объекта ранее срока, установленного договором. Например, срок ввода объекта в соответствии с проектным графиком - декабрь, при этом заказчик понимает, что если в результате оптимизационных мероприятий со стороны подрядчика и команды проекта ввод объекта удастся перенести на месяц, то проект раньше срока начнет генерировать прибыли, а значит и возвращать инвестиции, затраченные на его создание. В таких случаях условиями договора с подрядчиками предусматривается премия в адрес подрядчика в случае, если ввести объект удастся раньше директивного срока. Такая премия устанавливается в процентах от стоимости договора и, как правило, полностью или частично выплачивается персоналу подрядчика. Про- цент премирования может быть привязан к сроку, на который удалось сократить ввод. Например, за ввод на месяц ранее - 0,5\% от стоимости договора, за ввод на два месяца ранее - 1 \% от стоимости договора. Конечно, такие условия не могут служить оправданием некачественного выполнения работ подрядчиком. Условия качества и безопасности сохраняются в любом случае. Более того, при условии наличия у проекта системы оценки деятельности подрядчика, которая учитывает, в том числе, показатели качества работ, регулярные низкие показатели могут являться основанием для невыплаты соответствующей премии.

Аналоги такой стратегии уже применяются при реализации крупных проектов зарубежными нефтяными компаниями (Эксон Мобил, Шелл, Тотал, Ени, Петрочайна и др.) [12-20], в нашей стране пока опыт их применения незначителен [11].

ПАО «Газпром нефть» сегодня занимается активным внедрением таких инструментов управления потребностью и взаимодействия с рынком подрядчиков. Практически все новые проекты компании сегодня реализуются с применением части или полного набора таких инструментов. Ранее, по результатам реализации своих крупных проектов, таких как Новый Порт, Мессояха, ПАО «Газпром нефть» были сформированы извлеченные уроки, анализ которых показал, что от начала этапа «Оценка» до завершения этапа «Реализация» срок реализации занимает 12 лет. Этап «Поиск» добавляет к этому сроку еще около трех лет. Итого - около 15 лет до начала промышленной добычи нефти. Однако пример международных лидеров отрасли показывает, что сроки реализации проектов могут быть намного меньше. Исследования, которые проводит консалтинговая компания IPA, свидетельствуют, что ведущие нефтегазовые компании мира сегодня реализуют крупные проекты в сфере добычи уже менее чем за 5 лет. Для ускорения реализации и запуска крупных капитальных проектов ПАО «Газпром нефть» инициировала и реализовала внутренний организационный проект, получивший название Smart Fast Track (SFT) [21]. Smart Fast Track можно перевести как «умное ускорение». Идея не в том, чтобы добиться сокращения проектного цикла любой ценой. Важно, чтобы гонка за сроками не приводила к снижению качества работы - ухудшению показателей по добыче или затратам и в итоге потере ценности проекта. Одними из ключевых изменений были изменения в подходах работы с подрядными организациями и поставщиками. Bce изменения направлены на сокращения сроков - раннее или долгосрочное контрактование. Поиск подрядчиков на самые разные виды услуг, начиная с сейсморазведки и заканчивая строительно-монтажными работами, а также поставщиков оборудования должен начинаться заранее, еще до получения конечных технических условий. Конкурсы при этом проводятся по предварительным данным или объектам-аналогам, контракты первоначально включают лишь условия ценообразования на каждый вид работ - так, чтобы в будущем, когда появятся конкретные технические параметры или объемы работ, можно было легко рассчитать 
окончательную стоимость контракта. Такой подход позволяет на 8 месяцев сократить сроки реализации крупных проектов и убрать проблемы контрактования с критического пути проекта. Все новые крупные проекты ПАО «Газпром нефть» реализуются с применением выработанных подходов, например, проекты по освоению Тазовского и Северо-Самбургского месторождений. Применение выработанных подходов позволило на ранних стадиях разработки месторождений провести конкурсы и определить ключевых подрядчиков и поставщиков, с которыми сомневаться в успехе реализации данных проектов не приходится.

В результате трансформации подходов можно выделить следующие ключевые направления взаимоотношений ПАО «Газпром нефть» с подрядчиками:

1. Безопасность работ - безопасность персонала и окружающей среды, обеспечение которых превыше соображений экономического и технического характера.

2. Взаимоуважение и доверие. Сокращение формальностей и бюрократических барьеров при подрядных работах. Смещение вектора взаимоотношений с подрядчиками с надзора и контроля к взаимному доверию и взаимной ответственности друг перед другом. Независимость договоров от конкретных персоналий. Приоритет корректирующих мероприятий перед практикой штрафных санкций.

3. Максимальная информационная открытость компании, которая строится на принципах надежности и честности ведения дел. Прозрачный механизм изменений договоров подряда и решения возникающих споров.

4. Поощрение новаторства и инноваций среди подрядчиков в процессе взаимодействия с компанией. Помощь в адаптации подрядчиков, начинающих выполнение работ на объектах компании.

\section{СПИСОК ЛИТЕРАТУРЫ}

1. Инвестиционная деятельность нефтегазовых компаний России / И.В. Филимонова, И.В. Проворная, А.В. Комарова С.И. Шумилова // Проблемы экономики и управления нефтегазовым комплексом. - 2019. - № 5 (173). - С. 13-20.

2. Филимонова И.В., Эдер Л.В., Комарова А.В. Структура и динамика инвестиционных затрат в нефтегазовой отрасли России // Экологический вестник России. - 2019. - № 11. C. 4-10.

3. Зотов Ф.П. Организация проектов изменений в стратегическом управлении на российском предприятии нефтегазовой промышленности // Проблемы экономики и управления нефтегазовым комплексом. - 2011. - № 11. - С. 4-7.

4. Синельников А.А. Методические основы формирования портфеля инновационных проектов // Проблемы экономики и управления нефтегазовым комплексом. - 2014. - № 2. - С. 4-8

5. Герасимова М.В., Ямилова Я.В. Методические аспекты формирования системы стратегического управления рисками нефтегазовых проектов // Евразийский юридический журнал. - 2017. - № 5 (108). - С. 331-335.

6. Фадеев А.М., Череповицын А.Е., Ларичкин Ф.Д. Стратегическое управление нефтегазовым комплексом в Арктике. - Апатиты: Апатиты, 2019. - 289 с.

7. Молчанов К.К. Алгоритм управления портфелем проектов в национальных нефтегазовых компаниях // Актуальные исследования. - 2020. - № 6 (9). - С. 55-57.

8. Авдеева Л.А., Мусабирова К.М. Совершенствование процессов планирования и управления стоимостью проектов в про-

\section{Заключение}

Для успешной реализации проекта на ранних стадиях требуется проработка контрактных моделей и условий взаимодействия с подрядчиками. Проработка подходов должна иметь преемственность при переходе от стадии к стадии реализации проекта, а также необходимо достаточно времени для проработки всех инструментов. Кроме того, целесообразно все условия взаимодействия, условия тендерных процедур, а также последующего управления договорами предварительно прорабатывать с рынком подрядчиков/поставщиков. Это позволит вести открытый диалог с потенциальными подрядчиками по условиям дальнейшей работы, а также учесть и проработать все условия, которые не будут рабочими по различным причинам в дальнейшем. К таким причинам можно отнести и неготовность подрядчиков/поставщиков на некоторые предлагаемые вами условия. И это необходимо учитывать, так как на этапе выбора подрядчика/поставщика все несогласия или непонятные для подрядчика/поставщика условия выливаются в соответствующее увеличение расценок по договору.

Все эти аспекты должны быть учтены в соответствующей интегрированной стратегии заключения контрактов, которая станет сводным документом по управлению взаимоотношениями с подрядчиками, а также инструментом по контролю и управлению потребностью проекта. Кроме того, стратегия должна обеспечивать максимальную гибкость для проекта в отношениях с подрядчиками через соответствующие механизмы (открытые договоры, условия ценообразования и мотивации подрядчиков).

Новая система принципов и подходов определения партнеров для реализации крупных капитальных нефтегазовых проектов проходит успешную адаптацию в ПАО «Газпром нефть».

ектных организациях // Нефтегазовое дело. - 2016. - Т. 14. № 2. - С. 125-132.

9. Бородин С.С., Зубарева В.Д., Саркисов А.С. Процедура формирования и реструктурирования портфеля проектов нефтегазовой компании // Нефть, газ и бизнес. - 2017. - № 4. - С. 54-63.

10. Гасумов Р.А., Гасумов Э.Р. Применение инновационных решений при проектировании объектов нефтегазодобычи // Территория Нефтегаз. - 2017. - № 4. - С. 78-84.

11. Орлов С. Принцип партнерства. «Газпром нефть» меняет модель взаимоотношений с подрядчиками // Сибирская нефть. - 2019. - № 10 (167). - С. 40-44.

12. Fadyeyeva I., Horal L. Application of modern modeling in system of strategic management at oil and gas companies // Economic Annals - XXI. - 2014. - V. 1-2. - № 1. - P. 106-109.

13. Singh G., Tripathi A., Srivastava A. Integrated supply chain outsourcing - expanding the role of third party logistics in the upstream industry // Society of Petroleum Engineers Oil and Gas: Conference and Exhibition 2015; - Mumbai; India, 2015. Code 117754.

14. Katterbauer K. A decision support framework for the technical and economical optimisation of the supply chain and project scheduling for oil and gas projects under uncertainty - A case study approach // Offshore Technology Conference Asia 2016. Kuala Lumpur, Malaysia, 2016. - Code 138191. - P. 959-972.

15. Elhadad A. Risk based quality control in projects procurement // Society of Petroleum Engineers - SPE Abu Dhabi International Petroleum Exhibition and Conference 2017. - Abu Dhabi, 2017. Code 133061. 
16. Redutskiy Y. Conceptualization of smart solutions in oil and gas industry // Procedia Computer Science. - 2017. - V. 109. - P. 745-753.

17. Robinson P.R., Hsu C.S. Introduction to petroleum technology // Springer Handbooks. - 2017. - P. F1. - P. 1-83. DOI: 10.1007/978-3-319-49347-3_1

18. Al Mhdawi M.K. Proposed risk management decision support methodology for oil and gas construction projects // Lecture Notes in Mechanical Engineering - 10th International Conference on Engineering, Project, and Production Management, EPPM 2019. Berlin, 2020. - Code 238279. - P. 407-420.

19. Sustainable supply chain management strategy influence on supply chain management functions in the oil and gas distribution industry / M.S. Florescu, E.G. Ceptureanu, A.F. Cruceru,
S.I. Ceptureanu // Energies. - 2019. - V. 12. - № 9. - Article number 1632. DOI https://doi.org/10.3390/en12091632.

20. Nodeh M.J., Calp M.H., Sahin İ. A novel hybrid model for vendor selection in a supply chain by using artificial intelligence techniques case study: petroleum companies // Lecture Notes on Data Engineering and Communications Technologies. - 2020. V. 43. - P. 226-251. DOI: 10.1007/978-3-030-36178-5_19.

21. Алексеев А. Умное ускорение. «Газпром нефть» в два раза увеличит скорость реализации крупных проектов // Сибирская нефть. - 2017. - № 6 (143). - С. 22-27.

Поступила 22.10.2020 2.

Информация об авторах

Давыденков Е.В., заместитель генерального директора ООО «Газпромнефть-НТЦ». 
UDK 338.2:55398

\title{
OPTIMAL STRATEGY FOR SELECTING A CONTRACTOR FOR MAJOR CAPITAL OIL AND GAS PROJECTS
}

\author{
Evgeny V. Davydenkov, \\ evdavydenkov@gmail.com \\ Gazpromneft-STC LLC, \\ 75-79, lit. D, Moika river embankment, Saint Petersburg, 190000, Russia.
}

The relevance of this work is in changing the principals and approaches to selection of partners for implementation of large-scale infrastructure oil and gas projects.

The aim of this work is to prove the necessity of transforming the principals of relationship of oil and gas companies with the contractors in large oil and gas projects for joint solving the strategic business cases.

The method of the study is in optimization of the project decisions based on logical constructions of conception of the products' model of oil and gas companies activities.

Results. The most optimal tool for choosing the type of relationship with contractors and suppliers may be a contracting strategy, for a large infrastructure project - an integrated contracting strategy. This is a document that includes a comprehensive plan for implementation of the project, a map of all contracts with the necessary contractors and suppliers, a description of the approach to their selection, taking into account all possible synergies in the framework of contracts and, possibly, in the framework of projects. When determining the selection strategy for contractors and suppliers, it is necessary to take into account their current experience of cooperation with your company and other customers, their current burden on obligations to your company, the current capacity of the supplier or contractor and the ability to increase its capacity, the ability to consume and manage financial flows, experience in similar conditions.

Resume. When implementing a large-scale oil and gas infrastructure project, it is extremely important to develop a strategy for concluding contracts and models of relationships with contractors and suppliers at the earliest stages of the project, continuity in the transition from stage to stage of project implementation, development of conditions for interaction and subsequent management of contracts. All these aspects should be taken into account in a comprehensive contracting strategy, which should be a consolidated document for contractor management relationships, as well as a monitoring and project management tool. The maximum flexibility of the project in a relationship with contractors will be ensured through appropriate mechanisms - open contracts, pricing and motivation conditions for contractors. The new system for identifying partners for implementing major capital oil and gas projects has been successfully adapted in Gazpromneft.

\section{Key words:}

Large oil and gas project, project management, supply strategy, framework agreement, selection of contractors.

\section{REFERENCES}

1. Filimonova I.V., Provornaya I.V., Komarova A.V., Shumilova S.I. Investment activities of Russian oil and gas companies. Problems of economy and management of the oil and gas complex, 2019, no. 5 (173), pp. 13-20. In Rus.

2. Filimonova I.V., Eder L.V., Komarova A.V. Structure and dynamics of investment costs in the Russian oil and gas industry. Ecological Bulletin of Russia, 2019, no. 11, pp. 4-10. In Rus.

3. Zotov F.P. Organization of projects for changes in strategic management at a Russian oil and gas company. Problems of economy and management of the oil and gas complex, 2011, no. 11, pp. 4-7. In Rus.

4. Sinelnikov A.A. Methodological bases of forming a portfolio of innovative projects. Problems of economy and management of the oil and gas complex, 2014, no. 2, pp. 4-8. In Rus.

5. Gerasimova M.V., Yamilova Ya.V. Methodological aspects of forming a strategic risk management system for oil and gas projects. Eurasian legal journal, 2017, no. 5 (108), pp. 331-335. In Rus.

6. Fadeev A.M., Cherepovitsyn A.E., Larichkin F.D. Strategicheskoe upravlenie neftegazovym kompleksom $v$ Arktike [Strategic management of the oil and gas complex in the Arctic]. Apatity, Apatity Publ., 2019. 289 p.

7. Molchanov K.K. Algorithm for project portfolio management in national oil and gas companies. Current research, 2020, no. 6 (9), pp. 55-57. In Rus.

8. Avdeeva L.A., Musabirova K.M. Improving project cost planning and management processes in project organizations. Oil and gas business, 2016, vol. 14, no. 2, pp. 125-132. In Rus.

9. Borodin S.S., Zubareva V.D., Sarkisov A.S. Procedure for forming and restructuring the oil and gas company's project portfolio. Oil, gas and business, 2017, no. 4, pp. 54-63. In Rus.

10. Gasumov R.A., Gasumov E.R. Application of innovative solutions in the design of oil and gas production facilities. Territory of Neftegaz, 2017, no. 4, pp. 78-84. In Rus.
11. Orlov S. Principle of partnership. «Gazprom oil» changes the model of relations with contractors. Siberian oil, 2019, no. 10 (167), pp. 40-44. In Rus.

12. Fadyeyeva I., Horal L. Application of modern modeling in system of strategic management at oil and gas companies. Economic Annals - XXI, 2014, vol. 1-2, no. 1, pp. 106-109.

13. Singh G., Tripathi A., Srivastava A. Integrated supply chain outsourcing - expanding the role of third party logistics in the upstream industry. Society of Petroleum Engineers Oil and Gas. Conference and Exhibition 2015. Mumbai, India, 2015. Code 117754.

14. Katterbauer K. A decision support framework for the technical and economical optimisation of the supply chain and project scheduling for oil and gas projects under uncertainty - A case study approach. Offshore Technology Conference Asia 2016. Kuala Lumpur, Malaysia, 2016. Code 138191, pp. 959-972.

15. Elhadad A. Risk based quality control in projects procurement. Society of Petroleum Engineers SPE Abu Dhabi International Petroleum Exhibition and Conference 2017. Abu Dhabi, 2017. Code 133061.

16. Redutskiy Y. Conceptualization of smart solutions in oil and gas industry. Procedia Computer Science, 2017, vol. 109, pp. 745-753

17. Robinson P.R., Hsu C.S. Introduction to petroleum technology. Cham (Switzerland), Springer International Publishing AG, 2017. P. F1, 83 p. DOI: 10.1007/978-3-319-49347-3_1

18. Al Mhdawi M.K. Proposed risk management decision support methodology for oil and gas construction projects. Lecture Notes in Mechanical Engineering - $10^{\text {th }}$ International Conference on Engineering, Project, and Production Management (EPPM 2019). Berlin, 2020. Code 238279, pp. 407-420.

19. Florescu M.S., Ceptureanu E.G., Cruceru A.F., Ceptureanu S.I. Sustainable supply chain management strategy influence on supply chain management functions in the oil and gas distribution industry. Energies, 2019, vol. 12, no. 9, article number 1632. DOI https://doi.org/10.3390/en12091632. 
20. Nodeh M.J., Calp M.H., Sahin İ. A novel hybrid model for vendor selection in a supply chain by using artificial intelligence techniques case study: petroleum companies. Lecture Notes on Data Engineering and Communications Technologies, 2020, vol. 43, pp. 226-251. DOI: 10.1007/978-3-030-36178-5_19.
21. Alekseev A. Smart acceleration. Gazprom Neft will double the speed of implementation of major projects. Siberian oil, 2017, no. 6 (143), pp. 22-27. In Rus.

Received: 22 October 2020.

\section{Information about the authors}

Evgeny V. Davydenkov, deputy general director, Gazpromneft-STC LLC. 